\title{
EVALUASI TARIF ANGKUTAN UMUM LYN N BERDASARKAN BIAYA OPERASIONAL KENDARAAN, ABILITY TO PAY, DAN WILLINGNESS TO PAY (Studi kasus: Angkot Lyn N, Rute Terminal Bratang - JMP, Kota Surabaya) Abraham Kambuaya ${ }^{1}$, Theresia $M_{C A}^{2}$ \\ 1,2 Jurusan Teknik Sipil, Fakultas Teknik Sipil dan Perencanaan, Institut Teknologi Adhi Tama Surabaya Email : longteyes@gmail.com
}

\begin{abstract}
ABSTRAK: Terminal Bratang - JMP adalah lokasi yang terletak di kota Surabaya, dimana lokasi tersebut dapat digunakan untuk melakukan penelitian, sehingga penentuan tarif sendiri harus dilihat dari sisi operator dan penumpang agar memuaskan keduanya. Diketahui bahwa tarif yang berlaku dilapangan berbeda dengan tarif menurut PERWALI Surabaya Nomor 76 Tahun 2014. Dari penelitian ini bertujuan untuk mengevaluasi tarif bererdasarkan Biaya Operasional Kendaraan (BOK), Ability To Pay (ATP), dan Willingness To Pay (WTP) terhadap tarif yang berlaku dan mengetahui karakteristik penumpang. Pengumpulan data dilapangan yaitu wawancara dengan pemilik kendaraan untuk mengetahui biaya berdasarkan BOK dan penyebaran kuisioner kepada penumpang untuk mengetahui kemampuan, kemauan, dan karakteristik terhadap tarif yang berlaku. Hasil perhitungan berdasarkan BOK Rp 9.023,44 /pnp, berdasarkan pada hari kerja dan hari libur sebesar Rp 5.000 /pnp untuk umum dan pelajar/mahasiswa berdasarkan WTP tarif pada hari kerja sebesar Rp 5.906,664 /pnp untuk umum, sedangkan untuk pelajar/mahasiswa sebesar Rp 5.416,66 dan pada hari libur tarif sebesar Rp 5.736,664 untuk umum, sedangkan tarif untuk pelajar/mahasiswa sebesar Rp 5.000/pnp. Hasil perhitungan menunjukan bahwa tarif berdasarkan BOK dan WTP lebis besar dari tarif menurut PERWALI Rp 4.000 /pnp kategori umum dan tarif yang berlaku dilapangan $\mathrm{Rp} 5.000$ /pnp, maka pemerintah setempat harus mengevaluasi tarif BOK dan peningkatan fasilitas angkot lyn N dikota Surabaya.
\end{abstract}

Kata Kunci: Evaluasi, tarif Biaya Operasional, Kendaraan, Ability To Pay, Willingness To Pay

\section{LATAR BELAKANG}

Kota Surabaya memiliki perkembangan transpotasi sangat cepat, khususnya pada angkutan umum, sehingga diperlukan peraturan dan pengawasan yang maksimal agar dapat melayani pengguna jasa secara baik.

Untuk menentukan besaran tarif angkot diperlukan kebijakan dari pemerintah, hal ini sangat penting agar dapat memuaskan pengguna jasa dan penyedia jasa. Angkutan kota di Surabaya banyak dijumpai karena sangat ekonomis dan memiliki rute yang dilalui cukup banyak mencapai 57 rute, sehingga untuk angkot lyn $\mathrm{N}$ pada rute Terminal Bratang JMP sendiri memiliki jarak $12 \mathrm{~km}$ dengan waktu tempuh 40 50 menit. Rute tersebut melayani daerah yang melewati tengah kota yaitu pada kawasan kampus, rumas sakit, tempat perbelanjaan, stasiun, dan lain-lain.

Studi terdahulu mengenai tarif angkutan sudah dilakukan oleh Pandia, IJ dan Simamora RM (2014), dimana penelitian ini menunjukkan bahwa dari hasil perhitungan BOK pengusaha angkutan umum mendapatkan keuntungan dimana tarif yang berlaku saat ini wajar untuk menutupi Biaya Operasional Kendaraan. Studi terdahulu mengenai Ability To Pay dan Willingness To Pay juga sudah dilakukan oleh Lestari (2016). Berdasarkan hasil penelitian dilapangan dapat diketahui bahwa mayoritas penumpang BST adalah berjenis kelamin perempuan, jenis pekerjaan terbanyak yaitu pelajar, dominan tujuan perjalanan untuk keperluan bisnis, pendapatan terbanyak berkisar pada Rp 900.001,00 - Rp 1.009.050,00 dan penilaian pelayanan BST cukup memuaskan. Dari hasil perhitungan ATP sebsar Rp 2.000 /pnp untuk pelajar dan untuk umum sebesar Rp 3.670 pnp. Hasil perhitungan WTP untuk pelajar sebesar Rp 1.555 dan untuk umum sebesar Rp 3.458. Tarif yang berlaku saat ini lebih besar dari tarif berdasarkan perhitungan ATP dan WTP, sehingga dari hasil diatas maka perlu ada kajian ulang penerapan tarif di lapangan agar sesuai dengan kemampuan dan kemauan para penggunanya.
Penetapkan tarif angkot menurut PERWALI sebesar Rp 4000 /pnp, bagi pelajar tarif angkot memiliki potongan 50\% atau Rp 2.000 dengan jarak tempuh $15 \mathrm{~km}$, selebihnya penambahan Rp 200/pnp per km. Tetapi kenyataan dilapangan tidak sesuai dengan peraturan Walikota Surabaya tahun 2014, dimana tarif angkot naik menjadi Rp 5000 /pnp dan khusus buat pelajar tarifnya naik sebesar Rp 3000 /pnp. Melihat tarif yang berlaku dilapangan dapat diketahui bahwa kondisi ekonomi masyarakat khusus penyedia jasa semakin naik dan banyak penilaian angkutan umum (angkot) membuat masyarakat memiliki pilihan terhadap angkutan online dan kendaraan pribadi sehingga mempengaruhi Biaya Operasional Kendaraan serta kemampuan dan kemauan terhadap pengguna angkot. Dari permasalahan tersebut perlu melakukan penelitian mengenai Biaya Operasional Kendaraan (BOK), kemampuan (Ability To Pay) dan kemauan (Willngeness To Pay) terhadap tarif yang berlaku menurut PERWALI dan tarif yang berlaku saat ini untuk mengetahui secara detail tarif atau biaya apa saja yang dikeluarkan bagi pengguna angkot lyn $\mathrm{N}$, trayek Bratang - JMP berdasarkan BOK dan daya beli penumpang.

\section{METODE PENELITIAN}

\section{Survei Pendahuluan}

Survey pendahuluan merupakan tahapan awal penelitian untuk secara langsung mengetahui keadaan dilapangan pada angkot lyn N trayek Bratang - JMP. Survey pendahuluan dilakukan pada :

Hari/Tanggal

Jam

Jumblah surveyor

: Sabtu, 29 Februari 2020

: 09.00 - 11.00 WIB

Survey pendahuluan dapat dibagi menjadi beberapa bagian, yaitu:

1. Penentuan lokasi survey dan menentukan serta mengenal trayek yang telah dilalui oleh angkot.

2. Penentuan waktu survey dilakukan pada saat jam sibuk dan jam tidak sibuk. 
3. Penentuan jumlah surveyor dimana agar dapat membantu proses jalannya penganbilan data yang efissien dan efektif.

4. Pengecekan kembali form survey.

\section{Pengumpulan Data}

Pada tahapan ini pengumpulan data secara langsung dapat diperoleh dari hasil survey dilapangan. Pengumpulan data dibagi menjadi dua bagian, yaitu:

1. Data Primer

Adapun data primer, yaitu :

- Tujuan perjalanan

- Jumblah penumpang

- Biaya transportasi penumpang

- Penlilaian terhadap pelayanan angkot

- Penilaian terhadap tarif yang sesuai

- Frekuensi pengguna angkor

- Penghasilan penumpang per bulan

2. Data Sekunder

Adapun data sekunder, yaitu:

- Biaya Langsung

- Biaya Tidak Langsung

\section{Analisis Dan Pembahasan}

Analisis dan pembahsaan adalah hasil dari data survey yang didapat dari sopir dan penumpang angkutan umum. Data survey berdasrkan dari hasil:

1. Wawancara, yaitu data dari hasil survey Biaya Operasional Kendaraan (BOK) angkot lyn N, trayek Terminal Bratang - JMP.

2. Kuisioner, yaitu hasil dari responden untuk menganalisis besarnya nilai ATP dan WTP penumpang angkot lyn N, trayek Bratang - JMP.

\section{Lokasi Survei}

- Lokasi survey : Trayek Terminal Bratang - JMP

- Alamat

: Jl. Nginden Kota II, No.1 dan Jl.

Rajawali, Kec. Krembangan-Kota Surabaya.

- Jarak tempuh : $12 \mathrm{~km}$

Survey awal dilakuakan secara kecil pada tanggal 29 Februari 2020 seperti bawah ini,

- No. polisi kendaraan

$$
\text { : L } 1279 \text { UD }
$$

- Merek

Mitsubishi

- Tipe / model

: Colt T120 SS

- Tipe mesin

: $1300 \mathrm{CC}$

- Jenis bahan bakar : Bensin atau Premium

- Transmisi : Manual

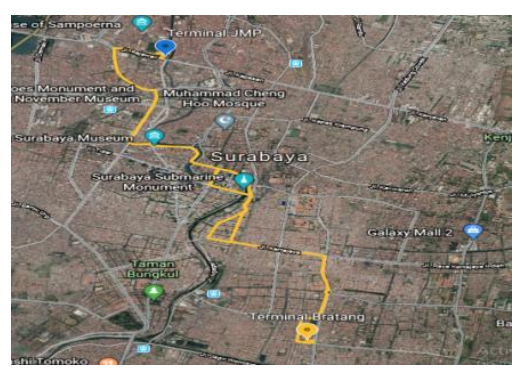

Gambar 1. Lokasi Survey, Terminal Bratang - JMP

\section{ANALISIS DAN PEMBAHASAN}

\section{Pelaksanaan Survei}

Survei untuk BOK dilaksanakan pada tanggal 29 Februari 2020, survei dilakukan jam 09.00 - 11.00 WIB. Sedangkan untuk survei ATP dan WTP dilaksanakan tiga hari dimana pada hari kerja dan hari libur. Survei pada hari kerja dilaksanakan dua hari yaitu tanggal 03 Agustus 2020 dan 04 Agustus 2020 yaitu survei pada jam sibuk 08.00 - 10.30 dan pada jam tidak sibuk 11.30 - 14.00 WIB. Survei pada hari libur dilaksanakan satu hari yaitu pada 09 Agustus 2020 dengan jam yang sama pada hari kerja, dimana survei pada jam sibuk 08.00 - 10.30 WIB dan jam tidak sibuk 11.30 14.00 WIB. Survei dilaksanakan dari terminal Bratang terminal JMP -Terminal Bratang dengan tenaga bantu survei dilapangan 2 orang.

\section{Pengambilan Data}

Pengambilan data atau sampel kepada pengguna jasa angkot lyn $\mathrm{N}$ dimana untuk mengetahui penilaian penumpang angkutan umum (angkot) terhadap tarif yang berlaku, ditinjau dari Biaya Operasional Kendaraan (BOK), Abality To Pay (kemampuan membayar) dan Willingness To Pay (kemauan membayar). Hasil survei data populasi pengguna jasa angkot lyn $\mathrm{N}$ terdapat pada Tabel 1:

Tabel 1. Populasi Pengguna Angkot Lyn N

\begin{tabular}{|l|c|c|c|}
\hline Jenis Hari & $\begin{array}{c}\text { Rata-rata } \\
\text { Penumpang/ang } \\
\text { kot/hari }\end{array}$ & $\begin{array}{c}\text { Jumlah } \\
\text { angkot }\end{array}$ & Populasi/hari \\
\hline Hari kerja & 10 & 2 & 20 \\
\hline Hari libur & 7 & 2 & 14 \\
\hline
\end{tabular}

Perhitungan besarnya sampel menggunakan rumus Slovin:

1. Hari kerja

$$
\mathrm{n}=\frac{\mathrm{N}}{1+\mathrm{Ne}^{2}}=\frac{20}{1+\left(20 \times 0,04^{2}\right)}=19,37984496
$$

2. Hari libur

$$
\mathrm{n}=\frac{\mathrm{N}}{1+\mathrm{Ne}^{2}}=\frac{14}{1+\left(14 \times 0,04^{2}\right)}=13,69327074
$$

Analisis Tarif Berdasarkan Biaya Operasional Kendaraan

1. Karakterisitik Kendaraan
a. Type
b. Jenis Pelayanan
: Mitsubishi Colt T120 SS
c. Kapasitas/Daya Angkut : 12 Orang
d. Load Factor : $70 \%$
e. Kapasitas oli mesin :4 Liter
f. Kapasitas BBM
: 42 Liter

2. Produksi Per Kendaraan
a. Km Tempuh/Rit (12 km-tempuh/trip)
$=24 \mathrm{~km} / \mathrm{rit}$
b. Frekuensi/Hari (4 trip/hari)
$=2$ rit
c. Km-Tempuh/Hari (a x b) $(\mathrm{KMH})$
$=48 \mathrm{~km} /$ hari
d. Hari Operasi/Bulan
$=24$ hari
e. Km Tempuh/Bulan (c x d) (KMB)
$=1.152$
$\mathrm{km} / \mathrm{bln}$
f. Frekuensi/Bulan (b x d)
$=48$ Rit
g. Km-Tempuh /Tahun (e x12Bln) (KMT)
$=13.824$
h. Penumpang /Rit
$\mathrm{km} / \mathrm{tahun}$
i. Penumpang /Hari (h $\mathrm{x}$ b) $(\mathrm{PH})$
j. Penumpang /Bulan (h x f) (PB)
$=10 \mathrm{pnp} / \mathrm{rit}$
$=20 \mathrm{pnp} / \mathrm{hr}$
$=480$
pnp/bulan 
k. Penumpang /Tahun (j x 12Bln) $(\mathrm{PT}) \quad=5.769$ pnp/thn

3. Biaya Per Kendaraan Mpu-Km

a. Biaya Langsung

- Biaya Penyusutan

- Harga Kendaraan (HK) = Rp 130.000.000

- Masa Penyusutan (MS) = 5 Tahun

- Nilai Residu (20\% dari HK) $(0,2 \times H K)$ $=\mathrm{Rp} 26.000 .000$

- Penyusutan Per Pnp $=\frac{130.000 .000-26.000 .000}{13.824 \times 5}$ $=\mathrm{Rp} 1504,63$ /Angkot-Km

- Biaya Awak Angkot

- Jumlah Awak

- Sopir = 1 Orang

- $\quad$ Kondektur $=0$ Orang Jumlah = 1 Orang

- Biaya Awak Angkot/Hari

- Pendapatan = Rp 100.000

- Tunjangan Kerja (makan, rokok, dll) $=\mathrm{Rp} 30.000$ Jumlah = Rp 130.000

- Biaya Awak Angkot/Bulan

- Pendapatan (100.000 x 24hari) $=\operatorname{Rp} 2.400 .000$

- Tunjangan kerja (30.000 x 24hari) $=\mathrm{Rp} 720.000$ Jumlah = Rp 3.120.000

- Biaya Awak Angkot/Tahun

- Pendapatan $1 \times 100.000 \times 24$ hari x 12 bulan $=\operatorname{Rp} 28.800 .000$

- Tunjangan kerja $1 \times 30.000 \times 24$ hari x 12 bulan $=\mathrm{Rp} 8.640 .000$

- Tunjangan sosial (THR) $=\mathrm{Rp} 0$ Jumlah = Rp 37.440.000

- Biaya Gaji /Pendapatan Pnp Biaya Awak Angkot /thn $=\frac{37.440 .000}{13.824}=\operatorname{Rp} 2.708,33$ /Angkot-Km

- Biaya BBM

- Pemakaian BBM = 10 Lt/Hari

- Harga BBM (premium) = Rp 6.550

- Pemakaian BBM /Rit (24/10Lt) = 2,40 Liter

- Biaya BBM /Angkot /Hari (10lt x 6.550) = Rp 65.500

- Biaya BBM /Km $\frac{\text { Harga BBM }}{\mathrm{KMH}}=\frac{65.500}{48}=\mathrm{Rp} 1364,58 /$ Angkot $-\mathrm{Km}$

- Ban

- Jumlah Ban = 4 Buah

- Daya Tahan Ban $\quad=20.000 \mathrm{Km}$

- Harga Ban = Rp 380.000

- Biaya Ban /Angkot $(1 \times 3)=$ Rp 1.520.000

- Biaya Ban / Km

$\frac{\text { Biaya Ban }}{\text { Daya Tahan Ban }}=\frac{1.520 .000}{20.000}=\mathrm{Rp} 76,00 /$ Angkot-Km

- Servis Kecil

- Servis kecil dilakukan setiap $\quad=5.000 \mathrm{Km}$
- Biaya Bahan :

Oli Mesin (4lt x Rp 50.000/lt) = Rp 200.000 Gemuk $(0,5 \mathrm{~kg} \times \mathrm{Rp} 9.500 / \mathrm{lt})=\mathrm{Rp} 2.000$

Minyak Transmisi (01t x Rp 9.500/lt $=\mathrm{Rp} 0$

Kanvas rem (2 ban $x$ Rp 115.000) $=R p 310.000$

- Ongkos service = Rp 145.000 Jumlah $=$ Rp 657.000

- Biaya service kecil /Pnp

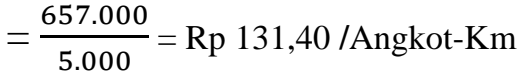

- Servis Besar

- Service besar dilakukan setiap $=10.000 \mathrm{Km}$

- Biaya Bahan:

Oli Mesin (4lt x Rp 50.000) = Rp 200.000

Oli Gardan (1lt x Rp 40.000) = Rp 40.000

Oli Persneling (1lt x Rp 80.000) $=\mathrm{Rp} 80.000$

Oli Filter (1bh $x$ Rp 30.000) = Rp 30.000

Gemuk $(0,5 \mathrm{~kg} \times \mathrm{Rp} 9.500 / \mathrm{lt}) \quad=\mathrm{Rp} 2.000$

Minyak rem 0,5lt (1 x 40.000/bh) $=\operatorname{Rp} 40.000$

- Ongkos service $=\mathrm{Rp} 500.000$ Jumlah $=\operatorname{Rp~} 892.000$

- Biaya Service Besar /Km Jum. Biaya Service Besar $=\frac{892.000}{10.000}=\mathrm{Rp} \mathrm{89,20/ \text {Angkot-Km }}$

- Biaya General Overhaul

- General overhaul dilakukan setiap $=300.000 \mathrm{~km}$

- Biaya overhaul:

- Suku cadang (5\% dari harga kend), $0,05 \times$ harga kend $=\operatorname{Rp} 2.000 .000$

- Perbaikan Body $=$ Rp 4.000 .000

- Ongkos service $=\mathrm{Rp} 700.000$

- Jumlah = Rp 6.700.000

- Biaya overhaul /Km $=\frac{\text { Biaya overhaul }}{\text { Jarak setiap overhaul }}$ $=\frac{6.700 .000}{300.000}=\mathrm{Rp} 22,33 /$ Angkot $-\mathrm{Km}$

- Penambahan Oli Mesin

- Penambahan oli mesin /hari $\quad=0,25 \mathrm{Lt}$

- $\mathrm{Km}$ tempuh /hari (KMH) $=48 \mathrm{Km}$

- Harga Oli /Lt = Rp 50.000

- Biaya Penambahan Oli Mesin /Pnp $=\frac{\text { Penambahan Oli } x \text { Harga Oli }}{\text { KMH }}=\frac{0,25 \times 50.000}{48}$ $=\operatorname{Rp} 260,42 /$ Angkot-Km

- Cuci Angkot

- Biaya cuci angkot /bulan = Rp 20.000

- Biaya Cuci Angkot /Km $=\frac{20.000}{1.152}=\mathrm{Rp} 17,36 /$ Angkot $-\mathrm{Km}$

- Retribusi Terminal

- Retribusi Terminal /Hari = Rp 2.000

- Biaya Retribusi Terminal/Pnp: $=\frac{2.000}{48}=\mathrm{Rp} 41,67 /$ Angkot $-\mathrm{Km}$

- STNK

- Biaya STNK /Angkot $/$ Thn $=$ Rp 210.000

- Biaya STNK /Km

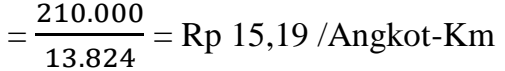


- KIR

- Frekuensi KIR/Thn $\quad=2$ Kali

- Biaya setiap kali KIR $\quad=$ Rp 90.000

- Biaya KIR/Thn = Rp180.000

- Biaya KIR /Pnp Angkot $=\frac{180.000}{13,824}=\operatorname{Rp~13,02/Angkot-Km}$

- Asuransi

- Asuransi Kend/Thn = Rp 120.000

- Asuransi Awak Angkot/Thn = Rp 0 Jumlah = Rp 120.000

- Biaya Asuransi /Pnp /Angkot

$$
\frac{\text { Asuransi Kend }}{\text { KMT }}=\frac{120.000}{13.824}=\operatorname{Rp~8,68}
$$

b. Biaya Tidak Langsung

- Biaya Pengelolaan /Tahun

Biaya izin Trayek = Rp 50.000

Biaya izin Usaha $\quad=\operatorname{Rp} 25.000$

Biaya lain-lain (Diluar unsur diatas) $=\mathrm{Rp} 500.000$

Sub Total $(b)=\operatorname{Rp} 575.000$

- Total Biaya Tidak Langsung /thn (a) + (b) $=\operatorname{Rp} 575.000$

- Total biaya tidak langsung /Angkot/Thn $=\frac{575.000}{1}=\operatorname{Rp} 575.000 /$ Angkot $/$ Thn

- Biaya tidak langsung /angkot-km $=\frac{575.000}{13.824}=\operatorname{Rp} 41,59$ /Angkot-Km

c. Rekapitulasi Biaya Langsung dan Biaya Tidak Langsung /Angkot-Km

Tabel 2. Rekapitulasi Biaya Langsung dan Biaya Tidak

\begin{tabular}{|c|c|c|}
\hline \\
\hline No & A. Biaya Langsung & /Angkot-Km \\
\hline 1 & Penyusutan & Rp 1504,63 \\
\hline 2 & Gaji dan Tunjangan & Rp 2708,33 \\
\hline 3 & Bbm & Rp 1364,58 \\
\hline 4 & Ban & $\operatorname{Rp} 76,00$ \\
\hline 5 & Service kecil & $\mathrm{Rp} 131,40$ \\
\hline 6 & Service besar & $\mathrm{Rp} 89,20$ \\
\hline 7 & General overhaul & Rp 22,33 \\
\hline 8 & $\begin{array}{c}\text { Penambahan oli } \\
\text { mesin }\end{array}$ & RP 260,42 \\
\hline 9 & Cuci kend & RP 17,36 \\
\hline 10 & Retribusi terminal & $\operatorname{Rp} 41,67$ \\
\hline 11 & STNK & $\operatorname{Rp} 15,19$ \\
\hline 12 & KIR & Rp 13,02 \\
\hline 13 & Asuransi & Rp 8,68 \\
\hline \multicolumn{2}{|r|}{ Jumlah } & $\begin{array}{c}\text { Rp 6.267,82 /Ankot- } \\
\text { km }\end{array}$ \\
\hline B & $\begin{array}{c}\text { Biaya Tidak } \\
\text { Langsung }\end{array}$ & Rp 41,59 /Angkot-km \\
\hline
\end{tabular}
Langsung

- Biaya Pokok /Angkot-km:

Biaya Langsung = Rp 6.267,82 /Angkot$\mathrm{km}$

Biaya Tidak Langsung $=\mathrm{Rp} 41,59$ /Angkot-km Jumlah

$=\operatorname{Rp} 6.309,41$ /Angkot$\mathrm{km}$

- Biaya Pokok Per Pnp-Km

$$
=\frac{6.309,41}{12}=\operatorname{Rp} 525,78 / \mathrm{Pnp}-\mathrm{Km}
$$

Perhitungan faktor muat (load factor) eksisting sebesar 70\% (Peraturan Jendral Perhubungan Darat Tahun 2002), dimana menentukan biaya pokok pada load factor sebesar:

- Tarif Pokok

$$
=\frac{6.309,41}{70 \% \times 12}=\frac{6.309,41}{8,4}=\mathrm{Rp} 751,12 / \mathrm{Pnp} / \mathrm{Km}
$$

- Biaya per penumpang :

$$
\begin{aligned}
& =(751,12 \times 12)+10 \% \\
& =\operatorname{Rp} 9.023,44 / \text { Pnp-Km }
\end{aligned}
$$

Perhitungan Ability To Pay

1. ATP Hari Kerja

Tabel 3. Rakapitulasi ATP pada hari kerja

\begin{tabular}{|l|c|c|c|c|c|}
\hline Pekerjaan & $\begin{array}{c}\text { It } \\
(\mathbf{R p})\end{array}$ & $\begin{array}{c}\mathbf{P p} \\
(\boldsymbol{\%})\end{array}$ & $\begin{array}{c}\mathbf{P t} \\
(\boldsymbol{\%})\end{array}$ & $\mathbf{T t}$ & $\begin{array}{c}\text { ATP } \\
(\mathbf{R p})\end{array}$ \\
\hline $\begin{array}{l}\text { Pelajar/ } \\
\text { mahasiswa }\end{array}$ & 6.200 .000 & 9,83 & 28,68 & 35 & 5.000 \\
\hline $\begin{array}{l}\text { Pegawai } \\
\text { swasta }\end{array}$ & 8.100 .000 & 10,37 & 62,5 & $\begin{array}{c}10 \\
5\end{array}$ & 5.000 \\
\hline IRT & 8.700 .000 & 6,78 & 43,22 & 45 & 5.666 \\
\hline Wiraswasta & 9.000 .000 & 8,33 & 60 & 90 & 5.000 \\
\hline Lainnya & 3.500 .000 & 10,71 & 26,66 & 20 & 5.000 \\
\hline
\end{tabular}

$$
=\frac{9.000 .000 \times 10,71 \% \times 26,66 \%}{90}=\mathrm{Rp} 5.000 / \mathrm{pnp}
$$

2. ATP Hari Libur

Tabel 4. Rekapitulasi ATP hari libur

\begin{tabular}{|l|c|c|c|c|c|}
\hline Pekerjaan & $\begin{array}{c}\text { It } \\
(\mathbf{R p})\end{array}$ & $\begin{array}{c}\text { Pp } \\
(\%)\end{array}$ & $\begin{array}{c}\text { Pt } \\
(\mathbf{\%})\end{array}$ & $\mathbf{T t}$ & $\begin{array}{c}\text { ATP } \\
(\mathbf{R p})\end{array}$ \\
\hline $\begin{array}{l}\text { Pelajar/ } \\
\text { mahasiswa }\end{array}$ & 1.650 .000 & 10,90 & 19,44 & 7 & 5.000 \\
\hline $\begin{array}{l}\text { Pegawai } \\
\text { swasta }\end{array}$ & 4.840 .000 & 14,66 & 59,15 & 84 & 5.000 \\
\hline IRT & 5.000 .000 & 12,9 & 41,86 & 54 & 5.000 \\
\hline Wiraswasta & 7.800 .000 & 8,33 & 50,9 & 56 & 5.000 \\
\hline Lainnya & 4.500 .000 & 9,79 & 27,27 & 24 & 5.000 \\
\hline
\end{tabular}

\begin{tabular}{|c|c|c|c|c|c|}
\hline \multirow[t]{2}{*}{ Pekerjaan } & \multicolumn{4}{|c|}{$\begin{array}{l}\text { Tarif yang dibayar } \\
\text { (Rp) }\end{array}$} & \multirow[t]{2}{*}{$\%$} \\
\hline & 5.000 & 6.000 & 6.500 & 7.000 & \\
\hline $\begin{array}{l}\text { Pelajar/ } \\
\text { Mhswa }\end{array}$ & 4 & 1 & 1 & & 30 \\
\hline Peg. Swasta & 1 & 2 & & 1 & 20 \\
\hline IRT & 2 & 2 & 1 & & 25 \\
\hline Wiraswasta & & 2 & 1 & & 15 \\
\hline Lainnya & 1 & 1 & & & 10 \\
\hline Jumlah & 3 & 8 & 3 & 1 & 100 \\
\hline
\end{tabular}

Sumber: Hasil perhitungan

$$
=\frac{7.800 .000 \times 8,33 \% \times 50,9 \%}{56}=\mathrm{Rp} 5.000 / \mathrm{pnp}
$$

\section{Perhitungan Willingnes To Pay}

1. WTP Hari Kerja

Tabel 5. Jumlah responden berdasarkan kemauan membayar pada hari libur

a. WTP Jenis Pekerjaan

- Kategori pelajar/mahasiswa $=\frac{(4 \times \mathrm{Rp} \mathrm{5000})+(1 \times \mathrm{Rp} \mathrm{6000})+(1 \times \mathrm{Rp} \mathrm{6.500})}{6}$ 
$=\operatorname{Rp} 5.416,66 / \mathrm{pnp}$

- Kategori pegawai swasta

$=\frac{(1 \times \mathrm{Rp} \mathrm{5000})+(2 \times \mathrm{Rp} \mathrm{6000})+(1 \times \mathrm{Rp} \mathrm{7.000})}{4}$
$=\operatorname{Rp} 6.000 / \mathrm{pnp}$

- Kategori IRT (Ibu rumah tangga)

$=\frac{(2 \times \mathrm{Rp} \mathrm{5000})+(2 \times \mathrm{Rp} 6000)+(1 \times \mathrm{Rp} \mathrm{6.500})}{5}$

$=\operatorname{Rp} 5.700$

- Kategori wiraswasta

$=\frac{(2 \times \mathrm{Rp} \mathrm{6.000})+(1 \times \mathrm{Rp} \mathrm{6.500)}}{3}$

$=\operatorname{Rp} 6.166,66 / \mathrm{pnp}$

- Kategori lain-lain

$=\frac{(1 \times \mathrm{Rp} 6.000)+(1 \times \mathrm{Rp} 6.500)}{2}=\mathrm{Rp} 6.250 / \mathrm{pnp}$

b. WTP Total Pekerjaan

$=\frac{5.416,66+6.000+5.700+6.166,66+6.250}{5}$

$=\operatorname{Rp} 5906,664 / \mathrm{pnp}$

2. Hari Libur

Tabel 6. Jumlah responden berdasarkan kemauan membayar pada hari libur

\begin{tabular}{|c|c|c|c|c|c|}
\hline \multirow{2}{*}{ Pekerjaan } & \multicolumn{4}{|c|}{ Tarif yang dibayar } & \multirow{2}{*}{$\%$} \\
\cline { 2 - 5 } & 5.000 & 6.000 & 6.500 & 7.000 & \\
\hline $\begin{array}{c}\text { Pelajar/ } \\
\text { Mhswa }\end{array}$ & 2 & & & & 13 \\
\hline Peg. Swasta & & 2 & & 1 & 20 \\
\hline IRT & 2 & 2 & & & 34 \\
\hline Wiraswasta & & 2 & 1 & & 20 \\
\hline Lainnya & & 1 & 1 & & 13 \\
\hline Jumlah & 4 & 7 & 2 & 1 & 100 \\
\hline
\end{tabular}

Sumber: Hasil Perhitungan

a. WTP pekerjaan

- Kategori pelajar/mahasiswa $=\frac{(2 \times \mathrm{Rp} \mathrm{5.000)}}{2}=\operatorname{Rp} 5.000 / \mathrm{pnp}$

- Kategori pegawai swasta $=\frac{(2 \times \mathrm{Rp} \mathrm{5.000})+(1 \times \mathrm{Rp} \mathrm{7.000})}{3}=\operatorname{Rp} 5.666,66 / \mathrm{pnp}$

- Kategori IRT $=\frac{(2 \times \mathrm{Rp} \mathrm{5000})+(2 \times \mathrm{Rp} 6000)}{4}=\mathrm{Rp} 5.500 / \mathrm{pnp}$

- Kategori wiraswasta $=\frac{(2 \times \mathrm{Rp} 6.000)+(1 \times \mathrm{Rp} \mathrm{6.500)})}{3}=\operatorname{Rp} 6166,66 / \mathrm{pnp}$

- Kategori lain-lain

$$
=\frac{(1 \times \mathrm{Rp} 6.000)+(1 \times \mathrm{Rp} \mathrm{6.500})}{2}=\mathrm{Rp} 6.250 / \mathrm{pnp}
$$

b. WTP Kategori Umum

Rp 5.000 + Rp 5.666,66 + Rp 5.500 + Rp 6166,66 + Rp 6.250

$=\operatorname{Rp} 5.736,664 / \mathrm{pnp}$

Rekapitulasi Tarif Berdasarkan BOK, ATP dan WTP

Tabel 7. Rekapitulasi tarif BOK, ATP, danWTP

\begin{tabular}{|c|c|}
\hline Jenis Tarif & $\begin{array}{c}\text { Nilai Tarif } \\
(\mathrm{Rp} / \text { Pnp) }\end{array}$ \\
\hline
\end{tabular}

\begin{tabular}{|l|c|}
\hline $\begin{array}{l}\text { Berdasarkan } \\
\text { perhitungan } \\
\text { BOK }\end{array}$ & $9.023,44$ \\
\hline $\begin{array}{l}\text { Berdasarkan } \\
\text { WTP } \\
\text { (penumpang } \\
\text { umum dan } \\
\text { pelajar }\end{array}$ & $\begin{array}{r}\text { Hari kerja: umum }=5906,664 \\
\text { pelajar }=5.416,66\end{array}$ \\
\hline $\begin{array}{l}\text { Berdasarkan } \\
\text { ATP } \\
\text { (penumpang } \\
\text { umum dan } \\
\text { pelajar) }\end{array}$ & $\begin{array}{r}\text { Hari kerja: umum }=5.736,664 \\
\text { pelajar }=5.000\end{array}$ \\
\hline $\begin{array}{l}\text { Tarif } \\
\text { berdasarkan }\end{array}$ & $\begin{array}{r}\text { Hari libur: umum }=5.000 \\
\text { pelajar }=5.000\end{array}$ \\
$\begin{array}{l}\text { PERWALI } \\
\text { 2014 }\end{array}$ & Kategori : umum $=4.000$ \\
\hline $\begin{array}{l}\text { Tarif yang } \\
\text { berlaku saat ini }=2.000\end{array}$ & \\
\hline
\end{tabular}

Dari Tabel 7 dapat dilihat bahwa tarif berdasarkan BOK, sedangkan berdasarkan PERWALI tahun 2014 untuk kategori umum sebesar Rp 4.000 dan tarif pelajar potongan $50 \%$ atau Rp 2.000, tarif yang berlaku saat ini yaitu Rp 5.000 kategori umum sedangkan untuk pelajar tarif sebesar $\mathrm{Rp}$ 4.000. Dari hasil perhitungan BOK dapat dilihat bahwa lebih besar dari tarif yang berlaku dan tarif berdasarkan perhitungan ATP serta WTP. Hal ini karena biaya penyusutan, gaji/tunjangan, BBM sangat besar sehingga berpengaruh pada hasil perhitungan BOK. Dilihat pada hasil perhitungan ATP sama dengan tarif yang berlaku sebesar Rp 5.000/pnp dan lebih kecil dari kemauan (WTP) membayar, sedang untuk hasil perhitungan WTP lebih besar dari tarif yang berlaku dan hasil perhitungan ATP. Hal ini terjadi dikarenakan kemauan membayar penumpang lebih besar tetapi harus diimbangi dengan fasilitas angkot lyn N. Menenurut PERWALI tahun 2014 tentang perbedaan tarif berdasarkan penumpang umum dan pelajar karena dilihat dari sisi usia dan kemampuan ekonomi, dimana untuk penumpang umum dapat diketahui bahwa berkecukupan untuk membayar dari segi usia dan mampu membayar dari sisi ekonomi karena ada penghasilan, begitupun sebaliknya untuk pelajar dimana karena pelajar dilihat dari sisi ekonomi dan usia belum mampu membayar karena tidak ada penghasilan.

Karakteristik Penumpang

1. Hari Kerja

- Jenis Kelamin Tabel 8. Persentase jenis kelamin responden

\begin{tabular}{|c|c|c|}
\hline Jenis kelamin & Jumlah & \% \\
\hline Perempuan & 12 & 60 \\
\hline Laki-laki & 8 & 40 \\
\hline Total & 20 & 100 \\
\hline
\end{tabular}

Tabel 8 diatas menunjukan bahwa jumlah responden jenis kelamin pada hari kerja, yaitu terdapat 20 jenis kelamin dimana presentase sebesar $60 \%$ untuk penumpang dengan jenis kelamin wanita dan $40 \%$ penumpang dengan jenis kelamin pria. Dari hasil peresentase tersebut dilihat bahwa penumpang dengan jenis kelamin perempuan yang 
terbanyak, hal ini karena kebanyakan perempuan ada yang belanja dipasar, berjualan, dan bekerja.

- Pendapatan Penumpang

Pendapatan penumpang pada pengguna jasa angkot lyn $\mathrm{N}$ dapat mempengaruhi kemampuan membayar, jika penumpang tersebut memiliki pendapatan tinggi, maka kemampuan membayar juga tinggi dan begitupun sebaliknya.

Tabel 9 Persentase pendapatan penumpang pada hari kerja

\begin{tabular}{|c|c|c|}
\hline $\begin{array}{c}\text { Pendapatan } \\
(\mathbf{R p})\end{array}$ & Jumlah & \% \\
\hline $500.000-1.000 .000$ & 8 & 40 \\
\hline $1.500 .000-2.000 .000$ & 5 & 25 \\
\hline $2.000 .000-2.500 .000$ & 3 & 15 \\
\hline $2.500 .000-3.000 .000$ & 3 & 15 \\
\hline$>3.000 .000$ & 1 & 5 \\
\hline Total & 20 & 100 \\
\hline
\end{tabular}

Dilihat pada Tabel 9, pendapatan pengguna jasa angkot lyn $\mathrm{N}$ memiliki pendapatan rendah, dimana dari hasil presentase pendapatan penumpang terendah, yaitu $40 \%$ atau sebesar Rp 500.000 - Rp 1.000.000. Di karenakan tidak membeli kendaraan pribadi.

- Responden Berdasarkan Tujuan Perjalanan dan Jenis Pekerjaan Pada Hari Kerja.

Tabel 10 Jumlah responden berdasarkan maksud perjalanan dan pekerjaan pada hari kerja

\begin{tabular}{|c|c|c|c|c|c|c|}
\hline \multirow[b]{2}{*}{ Pekerjaan } & \multicolumn{6}{|c|}{ Maksud Perjalanan } \\
\hline & $\frac{B}{D}$ व & 光 & $\bar{D}$ & 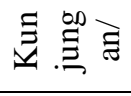 & $\frac{\mathscr{v}}{\mathscr{Q}}$ & ] \\
\hline Pelajar/Msw & & 4 & 1 & & 1 & \\
\hline Peg. Swasta & 3 & & & & & 1 \\
\hline IRT & & & 5 & & & \\
\hline Wiraswasta & 2 & & & 1 & & \\
\hline Lainnya & 1 & & & 1 & & \\
\hline$\%$ & 30 & 20 & 30 & 10 & 5 & 5 \\
\hline
\end{tabular}

Dari Tabel 10 dapat dilihat bahwa berdasarkan maksud perjalanan dan perkerjaan pelajar/mahasiswa dan IRT yang terbanyak dalam maksud perjalanan. Hal ini karena pelajar/mahasiswa memilih transportasi angkot lyn $\mathrm{N}$ untuk tujuan ke kampus.

Tabel 11 Jumlah responden berdasarkan kemauan membayar tarif dan jenis pekerjaan pada hari kerja

\begin{tabular}{|c|c|c|c|c|c|}
\hline \multirow[t]{2}{*}{ Pekerjaan } & \multicolumn{4}{|c|}{$\begin{array}{c}\text { Tarif yang dibayar } \\
\text { (Rp) }\end{array}$} & \multirow[t]{2}{*}{$\%$} \\
\hline & 5.000 & 6.000 & 6.500 & 7.000 & \\
\hline $\begin{array}{l}\text { Pelajar/ } \\
\text { Mhswa }\end{array}$ & 4 & 1 & 1 & & 30 \\
\hline Peg. Swasta & 1 & 2 & & 1 & 20 \\
\hline IRT & 2 & 2 & 1 & & 25 \\
\hline Wiraswasta & & 2 & 1 & & 15 \\
\hline Lainnya & 1 & 1 & & & 10 \\
\hline Jumlah & 3 & 8 & 3 & 1 & 100 \\
\hline
\end{tabular}

Pada Tabel 11 dilihat bahwa dari jenis pekerjaan, keinginan membayar dominan $\mathrm{Rp} 6.000$ dan yang terbanyak melakukan tujuan perjalanan adalah perlajar/mahasiswa karena jalur angkutan tersebut melalui kampus.

2. Hari Libur

- Jenis Kelamin

Tabel 12 Persentase jenis kelamin responden pada hari libur

\begin{tabular}{|c|c|c|}
\hline Jenis kelamin & Jumlah & \% \\
\hline Perempuan & 8 & 57 \\
\hline Laki-laki & 6 & 43 \\
\hline Total & 14 & 100 \\
\hline
\end{tabular}

Berdasarkan Tabel 12, hasil peresentase tersebut dilihat bahwa penumpang dengan jenis kelamin perempuan yang terbanyak, hal ini karena kebanyakan perempuan ada yang melakukan aktivitas bertujuan belanja dipasar, berjualan, dan bekerja.

- Pendapatan Penumpang

Pendapatan penumpang pada pengguna jasa angkot lyn $\mathrm{N}$ dapat mempengaruhi kemampuan membayar, jika penumpang tersebut memiliki pendapatan tinggi, maka kemampuan membayar juga tinggi. Begitupun sebaliknya, jika pendapatan rendah maka kemampuan membayar pun rendah.

Tabel 13 Persentase pendapatan penumpang pada hari libur

\begin{tabular}{|c|c|c|}
\hline $\begin{array}{c}\text { Pendapatan } \\
(\mathbf{R p})\end{array}$ & Jumlah & \% \\
\hline $500.000-1.000 .000$ & 4 & 29 \\
\hline $1.500 .000-2.000 .000$ & 5 & 36 \\
\hline $2.000 .000-2.500 .000$ & 2 & 14 \\
\hline $2.500 .000-3.000 .000$ & 3 & 21 \\
\hline$>3.000 .000$ & 0 & 0 \\
\hline Total & 14 & 100 \\
\hline
\end{tabular}

Dilihat pada Tabel 13, persentase pendapatan pengguna jasa angkot lyn $\mathrm{N}$ dapat ketahui memiliki pendapatan terbesar, yaitu Rp 1.500.000 - 2.000.000.

Tabel 14 Persentase responden berdasarkan maksud perjalanan dan pekerjaan pada hari libur

\begin{tabular}{|c|c|c|c|c|c|c|}
\hline \multirow[b]{2}{*}{ Pekerjaan } & \multicolumn{6}{|c|}{ Maksud Perjalanan } \\
\hline & 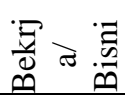 & $\frac{\breve{d}}{\omega} \frac{\pi}{0}=$ & $\bar{\otimes}$ & 壳 盯 & $\frac{y}{2}$ & ] \\
\hline $\begin{array}{l}\text { Pelajar/ } \\
\text { Mhswa }\end{array}$ & & & 1 & & 1 & \\
\hline Peg. Swasta & & & 1 & & 2 & \\
\hline IRT & & & 3 & & 1 & \\
\hline Wiraswasta & 2 & & & 1 & & \\
\hline Lainnya & & & 1 & & & 1 \\
\hline$\%$ & 14 & & 43 & 7 & 29 & 7 \\
\hline
\end{tabular}

Tabel 15 Jumlah responden berdasarkan kemauan membayar tarif dan jenis pekerjaan pada hari libur

\begin{tabular}{|c|c|c|c|c|c|}
\hline \multirow{2}{*}{ Pekerjaan } & \multicolumn{4}{|c|}{ Tarif yang dibayar } & \multirow{2}{*}{$\%$} \\
\cline { 2 - 5 } & 5.000 & 6.000 & 6.500 & 7.000 & \\
\hline $\begin{array}{c}\text { Pelajar/ } \\
\text { Mhswa }\end{array}$ & 2 & & & & 13 \\
\hline $\begin{array}{c}\text { Peg. } \\
\text { Swasta }\end{array}$ & & 2 & & 1 & 20 \\
\hline
\end{tabular}




\begin{tabular}{|c|c|c|c|c|c|}
\hline \multicolumn{2}{|l|}{ Lanjutan Tabel 15} \\
\hline IRT & 2 & 2 & & & 34 \\
\hline Wiraswast & & 2 & 1 & & 20 \\
\hline Lainnya & & 1 & 1 & & 13 \\
\hline Jumlah & 4 & 7 & 2 & 1 & 100 \\
\hline
\end{tabular}

Pada Tabel 15 dilihat bahwa dari jenis pekerjaan, keinginan membayar pada hari libur dominan Rp 6.000.

Tabel 16 Persentase karakteristik berdasarkan usia responden pada hari kerja dan libur angkot lyn $\mathrm{N}$

\begin{tabular}{|c|c|c|}
\hline Usia & Orang & \% \\
\hline $20-26$ & 9 & 26 \\
\hline $27-35$ & 7 & 21 \\
\hline $35-48$ & 11 & 32 \\
\hline $48-54$ & 6 & 18 \\
\hline$>54$ & 1 & 3 \\
\hline Jumlah & 34 & 100 \\
\hline
\end{tabular}

Tabel 17 Persentase status perkawinan responden pada hari kerja dan libur angkot lyn $\mathrm{N}$

\begin{tabular}{|c|c|c|}
\hline Status perkawinan & Orang & \% \\
\hline Menikah & 23 & 68 \\
\hline Belum menikah & 11 & 32 \\
\hline Jumlah & 34 & 100 \\
\hline
\end{tabular}

Tabel 18 Persentase karakteristik jumlah tanggungan responden pada hari kerja dan libur angkot lyn $\mathrm{N}$

\begin{tabular}{|c|c|c|}
\hline Jumlah tanggungan & Orang & \% \\
\hline Tidak ada & 14 & 41 \\
\hline 1 & 3 & 9 \\
\hline 2 & 7 & 20 \\
\hline 3 & 6 & 18 \\
\hline$>3$ & 4 & 12 \\
\hline Jumlah & 34 & 100 \\
\hline
\end{tabular}

Tabel 19 Persentase penumpang terhadap kualitas pelayanan angkot lyn $\mathrm{N}$ pada hari kerja dan libur

\begin{tabular}{|c|c|c|c|c|c|}
\hline \multirow{3}{*}{$\begin{array}{c}\text { Kualitas } \\
\text { pelayanan }\end{array}$} & \multicolumn{5}{|c|}{ Penilaian Penumpang } \\
\hline & 已 & 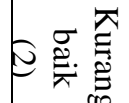 & \multicolumn{2}{|c|}{$\%$} & $\stackrel{-1}{\ddot{D}}$ \\
\hline & & & 1 & 2 & \\
\hline $\begin{array}{l}\text { Waktu tempuh } \\
\text { perjalanan }\end{array}$ & 15 & 19 & 44 & 56 & 34 \\
\hline $\begin{array}{l}\text { Kenyamanan dan } \\
\text { keselamatan }\end{array}$ & 28 & 6 & 82 & 18 & 34 \\
\hline Kebersihan & 12 & 22 & 35 & 65 & 34 \\
\hline Kelayakan & 24 & 8 & 75 & 25 & 34 \\
\hline \multicolumn{3}{|c|}{ Jumlah } & 100 & 100 & \\
\hline
\end{tabular}

Tabel 20 Persentase prioritas utama pelayanan angkot lyn $\mathrm{N}$ pada hari kerja dan libur.

\begin{tabular}{|c|c|c|}
\hline Prioritas utama & Orang & \% \\
\hline Waktu tempuh perjalanan & 7 & 21 \\
\hline Kenyamanan/keselamatan & 9 & 26 \\
\hline Kebersihan & 14 & 41 \\
\hline Kelayakan & 4 & 12 \\
\hline Jumlah & 34 & 100 \\
\hline
\end{tabular}

Tabel 20 dapat dilihat bahwa penumpang memiliki keinginan membayar lebih jika pelayanan pada angkot lyn $\mathrm{N}$ dapat ditingkatkan

\section{Pembahasan}

Dari tarif yang berlaku dan tarif yang dikeluarkan dari PERWALI tahun 2014 dapat dilihat bahwa berbeda dengan hasil perhitungan BOK, ATP, dan WTP. Hal ini dapat terjadi karena dari survei dilapangan, dimana dari perhitungan BOK mendapatkan tarif perpenumpang sangat besar yaitu $\mathrm{Rp}$ 9.023,44 /pnp dari tarif yang berlaku Rp 5.000 /pnp. Sedangkan tarif berdasarkan Peraturan Walikota Surabaya Nomor 76 Tahun 2014 ditentukan Tarif Batas Bawah (TBB) untuk mikrolet atau angkot sebesar Rp 4.000 /pnp jarak tempuh $15 \mathrm{~km}$ (lima belas kilo meter) dan Tarif Batas Atas (TBA) sebesar Rp 200 per km (200 rupiah per kilo meter). Maka dari hasil ini pemerintah kota Surabaya harus mengambil kebijakan atau memberikan solusi agar pengusaha penyedia jasa angkutan umum (angkot) dapat bertahan mencari penghasilan. Dari hasil survei dilapangan dapat diketahui bahwa banyak penumpang lebih memilih angkutan online atau kendaraan pribadi sehingga ketertarikan untuk menggunakan MPU atau angkot semakin berkurang dan hal ini mengakibatkan pendapatan penyedia jasapun angkutan semakin berkurang.

Tarif berdasarkan ATP dari hasil perhitungan:

1. Hari kerja

- Tarir penumpang umum : Rp 5.000/pnp

- Tarir pelajar

: Rp $5.000 / p n p$

2. Hari libur

- Tarif penumpang umum : Rp $5.000 / p n p$

- Tarif pelajar : Rp $5.000 / p n p$

Dari hasil tersebut dapat dilihat bahwa kemampuan membayar pada hari kerja dan libur sama dengan tarif yang berlaku saat ini.

Tarif berdasarkan WTP dari hasil perhitungan:

1. Hari kerja

- Tarif penumpang umum: Rp 5906,664/pnp

- Tarif pelajar

2. Hari libur

: Rp 5.416,66/pnp

- Tarif penumpang umum: Rp 5.736,66/pnp

- Tarif pelajar

: Rp $5.000 / p n p$

Dari hasil perhitungan WTP atau kemauan membayar dapat dilihat lebih besar dari hasil perhitungan ATP. Di mana hasil ini dapat lihat bahwa penghasilan penumpang besar dan mereka mau membayar lebih jika fasilitas, keamanan, kebersihan dan lain-lain harus ditingkat lagi. 


\section{KESIMPULAN DAN SARAN Kesimpulan}

Berdasarkan hasil perhitungan pada bab IV, hasil yang diperoleh sebagi berikut:

1. Tarif penumpang dari hasil perhitungan BOK kepada pengguna jasa angkutan umum (angkot) lyn $\mathrm{N}$ sebesar sebesar Rp 9.023,44 /pnp, sehingga dari perhitungan dapat dilihat bahwa tarif berdasarkan BOK lebih besar dari tarif yang berlaku, yaitu Rp 5.000 /pnp.

2. Tarif penumpang dari hasil perhitungan Ability To Pay (ATP) pada hari kerja dan hari libur sebesar Rp 5.000 /pnp. Dari hasil perhitungan, dapat dilihat besaran kemampuan membayar sama dengan tarif yang berlaku dilapangan yaitu Rp 5.000 /pnp, karena pendapatan penumpang rata-rata dengan kemampuan membayar. Sedangkan tarif yang berlaku pada hasil perhitungan Willingness To Pay (WTP) pada hari kerja sebesar Rp 5906,664/pnp untuk penumpang kategori umum, untuk kategori pelajar/mahasiswa sebesar Rp 5.416,66 /pnp dan WTP pada hari libur untuk kategori umum sebesar 5.736,664 /pnp dan tarif yang berlaku untuk pelajar sebesar Rp 5.000 /pnp, sedangkan tarif yang berlaku dilapangan sebesar Rp 5.000 /pnp. Dari hasil tersebut dapat dilihat bahwa kemauan membayar lebih besar dari tarif yang berlaku, sehingga dapat diketahui bahwa penumpang memiliki kemauan membayar lebih besar karena harus diimbangi dengan fasilitas angkot lyn N.

3. a. Persentase karakteristik responden berdasarkan usia pada hari kerja dan hari libur yaitu dominan pada usia 35 - 48 sebesar $32 \%$ karena diera modern seperti saat ini lebih dominan pengguna angkot rata-rata umur diatas 28 tahun.

b. Persentase jumlah responden berdasarkan jenis kelamin dominan jenis kelamin perempuan, yaitu pada hari kerja jenis kelamin perempuan berjumlah $60 \%$ dan pada hari libur berjumlah $57 \%$, hal ini terjadi kebanyakan perempuan ada yang melakukan aktivitas bertujuan belanja dipasar, berjualan, bekerja dan rekreasi.

c. Persentase responden berdasarkan status perkawinan pada hari kerja da hari libur yaitu dominan sudah menikah berjumlah $68 \%$.

d. Persentase responden berdasarkan jumlah tanggungan pada hari kerja dan libur dominan tidak ada tanggungan berjumlah $41 \%$.

e. Persentase rata-rata pendapatan responden per bulan pada hari kerja yaitu dominan $40 \%$ dengan pendapatan Rp 500.000 - Rp 1.000.000 dan pada hari libur berjumlah $36 \%$ dengan pendapatan Rp 1.500.000 - Rp 2.000.000.

f. Persentase jenis pekerjaan responden pada hari kerja yaitu dominan mahasiswa berjumlah $30 \%$ dan persentase pada hari libur yaitu dominan IRT berjumlah $29 \%$

g. Persentase responden berdasarkan tujuan perjalanan pada hari kerja yaitu dominan bekerja/bisnis berjumlah 30\% dan pada hari libur berjumlah $43 \%$ dengan tujuan perjalanan yaitu belanja.

h. Persentase responden berdasarkan penilaian kualitas pelayanan angkot lyn $\mathrm{N}$ pada hari kerja dan libur yaitu waktu tempuh perjalanan sebesar $19 \%$ kurang baik, keamanan sebesar $28 \%$ baik, kebersihan sebesar $22 \%$ kurang baik, dan kelayakan $24 \%$ baik.

i. Persentase berdasarkan biaya perjalanan pada hari kerja yaitu dominan $40 \%$ yaitu kemauan membayar Rp 5.000 - Rp 6.000, pada hari libur dominan $50 \%$ yaitu kemauan membayar Rp 6.000.

\section{Saran}

1. Tarif pada hasil perhitungan BOK dan WTP lebih tinggi dari tarif yang berlaku sehingga perlu ada kebijakan yang diambil dari pemerintah Kota Surabaya untuk mengevaluasi tarif angkutan umum.

2. Peningkatan pelayanan angkot dalam hal ini kenyamanan, kebersihan, waktu tempuh perjalanan dan kelayakan angkot.

3. Adanya pembatasan kendaraan pribadi dan angkutan online agar kapasitas muat (load factor) semakin meningkat.

\section{DAFTAR PUSTAKA}

Abbas salim, 2008. Manajemen Transportasi, graha ilmu Yogyakarta.

Direktorat Jenderal Perhubungan Darat SK.687/AJ.206/DRJD/2002, Pedoman Teknis Penyelenggaraan Angkutan Umum Di Wilayah Perkotaan Dalam Trayek Tetap Dan Teratur, Direktorat Perhubungan Darat.

Indra Jaya Pandia, Rico Mark Simamora (2014). Evaluasi Tarif Bus Antar Kota Dalam Propinsi (AKDP) Berdasarkan Biaya Operasional Kendaraan Trayek Medan-Doloksanggul, Universitas Sumatera Utara.

Lestari (2016), Analisis Kelayakan Tarif Batik Solo Trans (BST) Ditinjau Dari Ability To Pay (ATP) Dan Willingness To Pay (WTP), Universitas Muhammadiyah Surakarta.

Muhammad Rahmad Permata (2012), Analisa Ability To Pay dan Willigness To Pay Pengguna Jasa Kereta Api Bandara Soekarno Hatta - Manggarai, Universitas Indonesia.

Pedoman Skripsi Terdahulu Jurusan Teknil Sipil Institut Teknologi Adhi Tama Suarabaya.

Peraturan Walikota (PERWALI) Surabaya Nomor 76 Tahun 2014.

Rahman (2012), Analisa Biaya Operasi Kendaraan (BOK) Angkutan Umum Antar Kota Dalam Propinsi Rute Palu - Poso, Universitas Tadulako Palu

Rustian Kamaludin (1987), Ekonomi Transportasi, Jakarta: Ghalia Indonesia.

Tamin, O.Z. (1997). Perencanaan dan Permodelan Transportasi Edisi 1. Bandung : Penerbit ITB Bandung.

Warpani. (1990). Tujuan dan Peranan Angkutan Kota. Konsep Pelayanan Angkutan Kota website : perencanaankota.blogspot.co.id/2013/10/konseppelayanan-angkutan-kota.html. 